\title{
Role of plant host in determining differential responses to Ralstonia solanacearum and Glomus mosseae
}

\begin{abstract}
A pot study was aimed to investigate the role of tomato in determining differential response to bacterial wilt causal agent Ralstonia solanacearum pathogen and arbuscular mycorrhizal fungi (AMF) Glomus mosseae. Disease severity was measured after 10, 20 and 30 days of plant growth. The pathogen and dual treatment (R. solanacearum with G. mosseae) were not significantly different at the end of this experiment. Soil $\mathrm{pH}$ was greatly influencing the pathogen and AMF microbe. Glomus mosseae mycorrhizosphere was more alkaline (pH 5.9) compared to the pathogen mycorrhizosphere $(\mathrm{pH} 4.9)$. The concentration of bacterial cell in the R. solancearum soil was not different from the dual treatment after 60 days of plant growth. Spore germination was influenced by the interaction between the soil pathogen and AMF. Spores number in the dual treatment at 60 days was less than the original number added. Root colonization percentage in G. mosseae $(61 \%)$ was significantly more than the dual treatment (16\%). This provide an evidence about the role of plant host in increasing the spores germination influenced by many substances produced by the host root (root exudates). The results demonstrated that the role of plant in determination the relationship between soilborne pathogen and antagonistic microbe was critical.
\end{abstract}

Keyword: Arbuscular mycorrhizal fungi; Bacterial wilt; Disease severity; Root exudates 